
s/n Fracc. Progreso, Zacatecas, Zac., 98000, Mexico

E-mail: eanatoli@yahoo.com

\title{
THE STIMULATION OF STUDENTS' INTEREST IN THE TEACHING BY COMPETENCY-BASED APPROACH: LATIN AMERICAN PERSPECTIVE
}

\begin{abstract}
This article presents the results of scientific-pedagogical research, which consisted in identifying, what are the best strategies of stimulation of students' interest in the teaching by competency-based approach studying the works of Latin American scientists. With support in the pedagogic-comparative study the author has found out that in the Mexican education system the competency-based approach has been implemented since 2009 through the new national educational policies and Reform of Basic Education in which documents it is argued that competence means putting in play knowledge, attitudes, skills and values for achieving purposes in certain contexts and situations. One of the key tasks of the teacher is to lead and keep the attention of his/her students towards certain goals. Motivation to learning represents the socio-emotional or psychosocial variables (social identity, attitude to the subject, motivation), involved in learning on par with the educational variables (teacher, methodology, learning context); individual variables (subject learning abilities, aptitudes, needs, personality); socio-demographic variables (student's age, sex, socio-economic and socio-cultural level); sociopolitical context variables (importance in the society of knowledge that provides the subject). The study has showed that the best strategies for stimulation of students' interest in the learning by competency-based approach, following the Latin American scientists, are, among others, modeling, adapting, making the content of the studied discipline "accessible" to the student's needs; developing students' autonomy in learning; promoting conscious learning; establishing dynamic and equitable system of interrelations in the class; creating positive psychological environment; raising the illustrative and dynamic teaching; ensuring the self-control and self-regulation; using the error as part of the learning process (and not as punitive).
\end{abstract}

Key words: motivation in learning, stimulation of students' interest in the classroom, teaching by competency approach, Latin American education.

\section{INTRODUCTION}

In the Mexican education system the competency-based approach has been implemented since 2009 through the new national educational policies and Reform of Basic Education in which documents it is argued that competence means putting in play knowledge, attitudes, skills and values for achieving purposes in certain contexts and situations (Secretaría de Educación Pública, 2011).

One of the principles of competency-based teaching approach is to stimulate students' motivation in order to obtain more satisfactory learners' academic performance, because as Skinner said "[...] What good is building more schools, train more teachers and compose better educational materials if students do not want to study?" (Skinner, 1957). To 
get it is considered necessary to organize and structure the teaching and academic activities so as to contribute to the achievement of this goal, taking into account the personal and contextual factors influencing the students' interest in learning, in other words, the motivational elements.

\section{THE AIM OF THE STUDY}

The aim of this paper is to report the results of comparative scientific-pedagogical research, which consisted in identifying what are the best strategies of stimulation of students' interest in the teaching by competency-based approach studying the works of Latin American scientists.

\section{THEORETICAL FRAMEWORK AND RESEARCH METHODS}

It is importantly to note, that to the problem of motivation and the ways of its stimulation close attention pay psychologists and teaching methodologists: B. Ananiev (1969); C. Carnegie (2000); Yu. Galperin (1966); R. Gardner (1985); J. Hamers (1981); A. Leontiev (1977); A. Maslow (1991); P. Pintrich and A. De Groot (1990); L. Vygotskyi (1985), et al.

Besides, to this issue the following Latin American scientists devoted their works: A. Barca-Lozano (2012); M. Carretero (2009); E. De Corte (1995); M. De la Barrera and S. Croatto (2002); D. Donolo and M. De la Barrera (2000); M. Espí and M. Azurmendi (1996); G. González Cabanach (1996); P. Marins de Andrade (2010); J. Ospina Rodríguez (2006); J. Núñez (1995); J. Tapia-Alonso (2001); G. Vallejo Portuondo (2011); et al.

This work is a documentary-bibliographic study, which was performed under the critical-dialectical approach, using research methods of analysis, synthesis, comparison and generalization that were necessary to study the original texts and official documents, organization of the studied material and its exposure.

\section{RESULTS}

Motivation (from Latin movere, "move") is conceptualized by modern psychology (Bekh, 2004; Barca-Lozano, 2012; Carnegie, 2000; Carretero, 2009; Hamers, 1981; Tapia, 2005, et al) as the effort consented by an individual to achieve a goal. It belongs to the impulses that are learned (secondary needs that guide human behavior, namely, the acquired social needs). Attitudes determine motivation. Whenever motivation is discussed, emphasis is placed on the intentional nature of the conduct. When an individual is motivated to achieve a goal, his/her activity is directed towards it.

Both primary and secondary needs motivate people to behave in a way that will achieve the goals that meet those needs. An individual is motivated when he/she reveals by words or actions, that he/she wants to achieve some goal. Motivate someone means to increase their drive to achieve a goal or create a need that did not exist previously. The goal is the incentive for motivated behavior, and the specific need is the reason for it (Hamers, 1981).

Current theories of motivation posit three types of basic needs: power, affiliation and achievement. The intensity of each of these three elements varies from person to person, depending on his/her social and cultural experiences, creating very different motivational states. That is, all human beings tend, to a greater or lesser extent, to meet our needs to control the behavior of others (power), feel members of a group (affiliation) and get materials or other goods (achievement) (Carretero, 2009).

The achievement motivation is the most important for learning. The tendency of a person to act to learn depends on the following issues: the intensity of his/her motivation in this regard; his/her expectation of getting what is proposed; the reward expected. The motivation to learn, is a combination of desire to learn, the effort made in this direction and 
favorable attitudes toward learning. One of the key tasks of the teacher is to lead and keep the attention of his/her students towards certain goals (Gardner, 1985).

Motivation to learning represents the socio-emotional or psychosocial variables (social identity, attitude to the subject, motivation), involved in learning on par with the educational variables (teacher, methodology, learning context); individual variables (subject learning abilities, aptitudes, needs, personality); sociodemographic variables (student's age, sex, socio-economic and socio-cultural level); sociopolitical context variables (importance in the society of knowledge that provides the subject) (see figure 1) (Azurmendi, 1996).
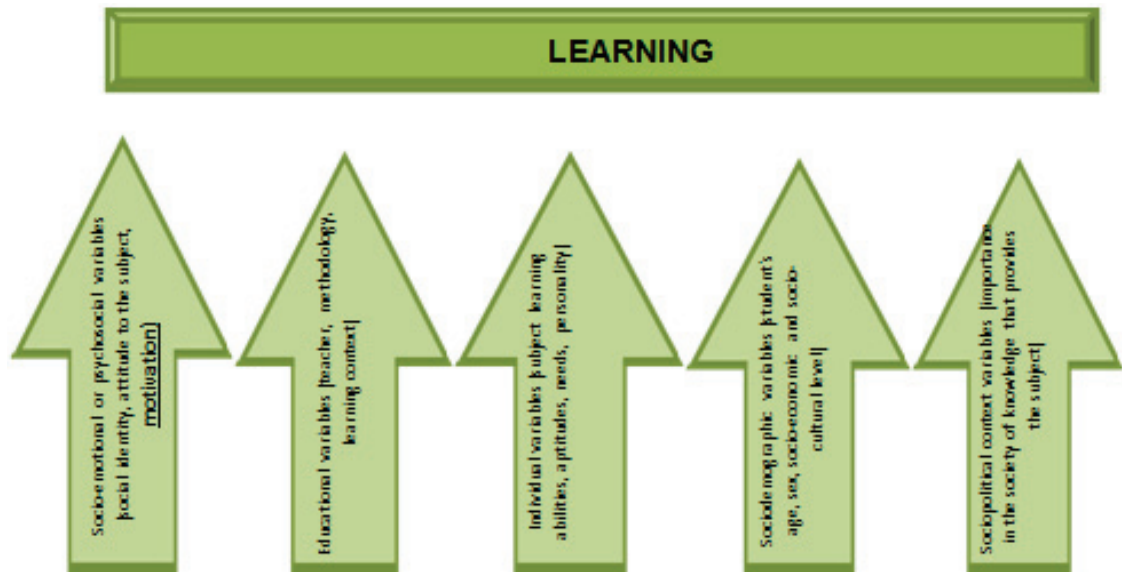

Figure 1. Place of Motivation among the Variables, which Determine the Learning Process

Among the individual variables are student's needs:

The need to succeed. This need can be considered as a personality trait that manifests as a desire to succeed or win in a particular activity (in this case, learning). The specific activity does not really matter; the individual with an intense need to succeed seeks success in a career as when playing chess, studying for a test or working. For him/her, an activity is the opportunity for achievement rather than something that stands on its own. The failure before any attempt is much more painful for him/her than for any other student who does not have this kind of need. A high level of aspiration is typical in people with a strong need for success, set goals and difficult struggle to obtain its. Early parental pressure for independence and achievement is a primary factor in the development of the need for success. Those individuals who put emphasis on success, achieved more effectively than others because they persist in tasks that others tend to drop when success is not immediate. The need to succeed is an important determinant of school performance and future life. An essential component of success is the awareness that the extra effort will produce better results (Barca-Lozano, et. al., 2012).

The need to adapt to the group norms. It is important for students not be different from their peers in behavior, dress and many other aspects, because in our society an individual is rewarded by the fact think and act the same way as his/her peers. The students feel safe in their identification with the group and fear any possibility of exclusion. Conformism, unfortunately, has acquired some negative connotations. When a person described as "conformist", the picture that emerges is of rigidity, conventionality and lack 
of imagination. Actually, it is possible and desirable for an individual showing conformism in some ways but not in others. A man can obey the law, conform to social mores and yet being a creative scientist whose work is completely original (Carretero, 2009).

The need for self-realization. Students are highly motivated to achieve goals that are compatible with their self-concept. Attitudes towards specific subjects to the school, and the perception that the student has of himself, have significant consequences on learning. Of these three factors, the perception that students have of themselves, is the most powerful. It is important to note that the perception that a student has of himself (his academic self-concept) is not innate, but is the result of his/her school learning experience. The history of successes and failures and the positive or negative effects creates, brightens or darkens the future learning. The conviction that one can improve if tries, encourages progress, both in intellectual performance and manual skills. The role of self-confidence in this aspect of motivation is obvious. If a student does not believe to be able to improve his/her school performance, he/she will not make the effort (Vallejo Portuondo, 2011).

For the study of motivation in learning, it is important to consider the following categories: perceived competence (causal attributions), goals and intentions with which a student is involved in performing a task (the focus of motivation), the affective-emotional reactions that occur therein and self-concept (already mentioned above) (see figure 2) (Pintrich, De Groot, 1900).

The first concerns the interpretations and assessments done by one person of his/her academic results and those that determine his/her motivation. The second has to do with the type of cognitive resources that triggers the subject when dealing with the various learning, the type of strategies to use that will achieve meaningful learning. The third and fourth refer to personal and subjective assessment that the student makes about the other (matter, teacher, peers) and about himself, and that determine the success or failure in his/her studies.

\section{MOTIVATION IN LEARNING}

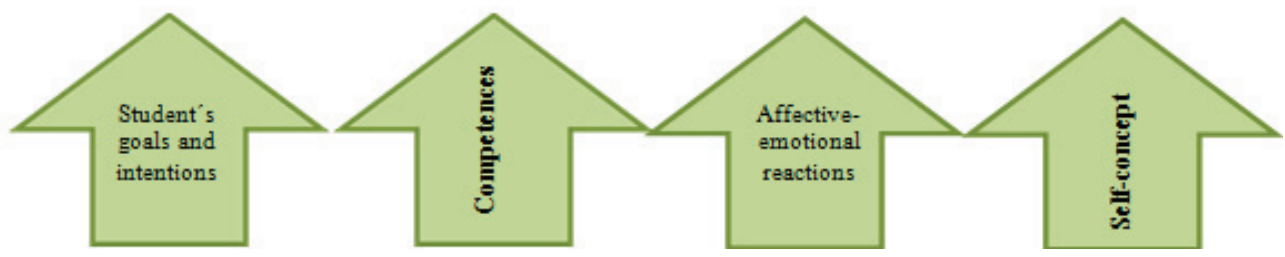

Figure 2. The Categories to be Considered for the Study of Motivation in Learning

So, academic self-concept and causal attributions directly influence the motivational orientation of the student or his/her adoption of different types of goals, that, in turn, determine the type of learning strategies that will launch the student, prescribing in this way learning outcomes is getting. Here arises the question: what is the teacher's role in this process of student's academic self-concept building and development of his/her motivation in learning and how could the teacher activate and press this process? Let us analyze right away the position thereon of Latin American methodologists using research methods of analysis, synthesis, comparison and generalization that were necessary to study the original texts and official documents, organization of the studied material and its exposure. 
The study showed that according to the Latin American methodologists (A. BarcaLozano (2012); M. Carretero (2009); E. De Corte (1995); M. De la Barrera and S. Croatto (2002); D. Donolo and M. De la Barrera (2000); M. Espí and M. Azurmendi (1996); G. González Cabanach (1996); P. Marins de Andrade (2010); J. Ospina Rodríguez (2006); J. Núñez (1995); G. Vallejo Portuondo (2011); et al), to form the positive attitude of the students towards the studied matter, from which comes motivation and hereinafter their successful learning, the teacher must lead and hold the attention of students towards certain goals taking into account their interests, expectations, hopes, their psychological, physiological specificities, age, nationality, social and economic particularities.

In addition, it must be taken into account the importance of the fruitful interaction of the three components of the teaching-learning process: students with their learning reasons (prior knowledge); professor with his/her methods, techniques, means and methods of teaching (support instrument to establish the relationships between prior knowledge of students and learning new material); matter and its units (new knowledge).

The construction of knowledge in the classroom depends on exchanges between teacher and student around the learning content; it is necessary to analyze the interactions established between the three vertices of the triangle of knowledge construction process. In the course of these interactions are explained, take shape, and eventually change not only the prior knowledge of students, but also their attitudes, expectations and motivations to learning. During these interactions, the teacher conducts mediating role between student's activity and culturally organized collective knowledge (Ospina Rodríguez, 2006).

The results of the analysis also allow us to affirm that a close relationship between the motivational aspects of behavior and the effectiveness of the methods of teaching and learning exists. Stimulating students' motivation is achieved through the problematic nature of the exercises and teaching situations; control and self-control of acquired knowledge, abilities and skills; the use of cognitive games and audiovisual material; the introduction of students in an independent study; fostering collective work; creation of positive psychological atmosphere in the classes (Marins de Andrade, 2010).

The teacher's task is to develop the internal motivation of students, which comes from the same learning activity and has crucial importance as it defines the position of the student facing discipline (positive, neutral, negative) and ensures progress in learning.

When the same learning activity encourages students to continue studying (for example, they like the act of reading, seek additional information, learn more about the object/subject studied), it is clear that the students have a positive attitude towards the study of this or that matter. Under these conditions, the students are ready to move forward and achieve success in their learning, and the work of the teacher is to keep this motivation and increase it (Barca-Lozano, et. al., 2012).

Latin American scientists believe that motivating students in their learning means that teacher must show interest, enthusiasm for students' achievement. The student's interests direct his/her activities and keep his/her attention. When learners perceive the interest of the teacher for his/her subject, for the content that teaches, they are also interested in this topic, they want to know more about it, and this intrinsic need is met by learning, creating motivation to approach.

Stimulate students' interest in learning means also create a positive climate in the classroom. If student associates the classroom with stress and unpleasant events, endeavor not go to school as often as possible, he/she can learn to "be sick" to stop concur or may even decide he/she does not want to continue studying, in other words, presents trends avoidance. 
To create in student the confidence in himself, his own performance, discard his fear of failure and possible ridicule, it is necessary to set the intermediate goals and give him the opportunity to reward for the partial success. It is also important to take into account the existing interests of the students and find ways to relate its which the subject to be taught, scanning the appropriate method for each situation, articulate theoretical knowledge with practical exercise as a strategy to maintain the motivation to learn. It is also substantial to create new interests as a result of classroom experiences which will motivate learners; arouse interest through concrete experiences applicable to situations of life and/or daily practice (Carretero, 2009).

In addition, an intimate relationship exists between the interests and curiosity of the student. When the student experiences curiosity about certain scientific phenomenon or the result of a problem of everyday life, his/her interest is maintained and his/her behavior is oriented towards satisfaction of such curiosity. It is important that the student's curiosity is satisfied and rewarded; otherwise, his/her tendency to ask and formulate questions will decrease. The teacher should praise students for a "good question" as much as for a correct answer. The positive reinforcement of well thought question can contribute to an atmosphere of much more interesting learning than occurs in a class where the correct answer is the norm (Vallejo Portuondo, 2011).

The students' curiosity can wake direct sensory experiences (like curiosity is the desire to manipulate, to act on what surrounds). The student is interested in handling objects, carry out experiments and control the effects of a situation. The desire to model the clay itself in the pottery class is not very different from doing an experiment without direct help. Whenever possible, students should be allowed to carry out experiments, build models related to the subject and experience things directly, at least through abstract analysis.

The teacher must be alert for opportunities to provide students with direct sensory experiences. Innovations are one of the ways to arouse curiosity: young people are motivated to participate in new activities, different from their previous experiences. Sometimes, however, student bores even though the material is new, because the teaching method is not relevant. Audiovisual materials, multimedia programs and various practical activities can awaken and/or sustain student's interest. This does not mean that teachers have to prepare a range of original activities for each class, but rather, innovation should be introduced where possible. The teacher should seek to present the material in each class in the way that is most meaningful and interesting for students, plan activities, demonstrations, audiovisual materials so as to enrich the presentation of the issue and draw attention to its fundamental elements (Marins de Andrade, 2010).

We have also identified that regarding the relationship of goals with motivation, Latin American methodologists support that teachers should encourage the achievement of goals that are reasonable, that is accessible to the student's ability, whether the need for success is high or low. The teacher as facilitator of learning has to guide the student to an appropriate effort, seek satisfactions and no frustrations; submit responsive to students' abilities to maintain a share of challenge goals.

It is inconsistent that the teacher promotes compliance with certain standards and encourages the same time, originality and independence. The impulse to conformism facilitates the process of teaching and learning when the student is motivated to participate in activities because his/her peers do. When the teacher can show students that certain goals are within reach, they can accept and feel, while motivated to get them in order to realize the new concept of themselves (Ospina Rodríguez, 2006). 
In order to motivate higher performance in students, the teacher can encourage competition between them, but following the strategies that do not limit the number of winners and that the competition is interesting in itself and does not dominate the activity. Competition between teams can be used in some situations because no individual is a loser.

A very useful stimulus for competition is the desire to improve one's own past performance. A person, who competes with his own past performance, has a reasonable hope of success, since he only needs to do things a little better than has already been able to do. Even if the absolute level of performance is not high, the student should receive praise and approval by the fact that his relative performance has increased. If the teacher keeps work samples, he/she can show the student how he/she has improved, which impresses more to say simply that it is better doing things. Since any student can improve, it is not necessary to have losers in this kind of competition (Marins de Andrade, 2010).

We found out besides that Latin American scientists pose that to greater effort in learning can motivate also qualifications, but as long as the teacher provides an objective analysis of results of the work for which the students were obtained these qualifications. In these circumstances the students are motivated to perform activities in the classroom and study at home in order to receive high scores or other symbolic rewards.

In general, the qualifications possess certain attributes of resources that stimulate motivation, but also present some problems. A qualification obtained at the end of a school year or other period that lasted very long, does not serve as useful for the organization of future performance feedback. On the other hand, the qualifications are often not specific, provide general information that the performance was excellent, enough or low, but do not indicate exactly what was wrong or right. The qualifications to be useful must be frequent and be accompanied by clear explanations about its meaning, should not become a source of competition in the classroom and acquire a special meaning oblivious to the learning task (Vallejo Portuondo, 2011).

In the process of students' learning the teacher must also provide for the so-called reduced stress caused by low motivation, boredom, frustration, fatigue, dissatisfaction with their progress. When the effort does not entail an advance, students, especially younger ones, quickly accept defeat and not make more efforts. One cause of the feeling that "there is no progress" is the fact that the yield does not increase steadily during learning. However, it is a natural part of learning and the teacher should encourage students to continue their efforts.

One of the most important factors in low motivation is the distance between the individual and his/her goal. Often goals are psychologically too distant to support this effort. To sustain motivation, it is essential to establish intermediate, closer goals, and convinced students that the eventual reward justifies the current effort (Carretero, 2009).

\section{CONCLUSIONS}

So the pedagogic-comparative study allows us to conclude that the best strategies for stimulation of students' interest in learning by competency-based approach, following the Latin American scientists, are:

- managing the learning process through its programming, systematizing, organizing cyclically and evaluating each cycle;

- modeling, adapting, making the content of the studied discipline "accessible" to the student's needs;

- providing the problematic nature of learning material; 
- individualizing the learning process, taking into account that each student is an individual who possesses certain common and particular capabilities (personal experience, context, interests, emotions and feelings, own world view, status in the group);

- developing students' autonomy in learning;

- ensuring that the content and its organization are novel;

- promoting conscious learning;

- providing the means to meet existing needs in students so that they may comply simultaneously with the objectives of teaching content;

- establishing dynamic and equitable system of interrelations in the class; promoting a communicative teaching: establishing fruitful communication between student and teacher, intergroup, with other teachers, etc.; creating positive psychological environment;

- raising the illustrative and dynamic teaching through audio material, videos, photos, drawings, ICT and other materials;

- providing students direct sensory experiences, allowing them carry out experiments, build models related to the subject and experience things directly;

- ensuring the self-control and self-regulation; using the error as part of the learning process (and not as punitive).

From the work done, it is considered that the perspectives of future research on motivation in learning may be specific strategies to motivate different contingents of students, in particular, marginalized learners, higher education students, etc.

\section{REFERENCES}

1. Barca-Lozano, A. et. al. (2012). School Motivation and Performance: Impact of Academic Goals, Learning Strategies and Self-Efficacy. Annals of Psychology, Volume 28, No 3, pp. 848-859.

2. Carretero, M. (2009). Constructivism and Education. Buenos Aires : Paidós, 222 p.

3. Espí, M., Azurmendi, M. (1996). Motivation, Attitudes and Learning of Spanish as a Foreign Language. Journal RESLA, No 11, pp. 63-76.

4. Gardner, R. (1985). Social Psychology and Second Language Learning, London : Arnold Publishers, $216 \mathrm{p}$.

5. Hamers, J. (1981). Psychological Approaches to the Development of Bilinguality. In: Baetens Beardsmore, H. (Ed.), Elements of Bilingual Theory. Brussels, Belgium : Vrije Universiteit te Brussel, pp. 28-47.

6. Marins de Andrade, P. (2010). Learning Strategies and Motivation Development: an Empirical Study with Brazilian E/LE Students. PORTA LINGUARUM, No 14, pp. 141-160.

7. Ospina Rodríguez, J. (2006). Motivation, Motor of Learning. Health Sciences Journal, Volume 4, pp. 158-160.

8. Pintrich, P., De Groot, A. (1990). Motivational and Self-Regulated Learning Components of Classroom Academic Performance. Journal of Educational Psychology, No 82, pp. 33-40.

9. Secretaría de Educación Pública [Ministry of Public Education]. (2011). Currículum de educación básica (Ley General del Servicio Profesional Educativo, Ley General del Instituto Nacional de Evaluación) [Curriculum of basic education. First Edition, SEP (General Law of Professional Teacher Service, General Law of the National Institute for Evaluation)], Mexico, SEP, $352 \mathrm{p}$.

Group, 193 p.

10. Skinner, B. (1957). Verbal Behavior, Action. Massachusetts : Copley Publishing

11. Vallejo Portuondo, G. (2011). Learning from the Perspective of Professional Motivation and Attitudes. MEDISAN, Volume 15, No 3, pp. 105-115. 